\title{
Evaluation of genetic diversity in Mexican wheat (Triticum aestivum L.) genotypes for qualitative and quantitative traits
}

\author{
MUDRA KHARE ${ }^{*}$, N.R. RANGARE ${ }^{2}$ AND RAVI P. SINGH ${ }^{1}$
}

${ }^{1}$ Department of Genetics and Plant Breeding, Institute of Agricultural Sciences, Banaras Hindu University, VARANASI (U.P.) INDIA

${ }^{2}$ Department of Genetics and Plant Breeding, College of Agriculture, Allahabad Agricultural Institute-Deemed University, ALLAHABAD (U.P.) INDIA

\section{ARITCLE INFO}

Received : 30.08 .2014

Revised : 29.01.2015

Accepted : 16.02 .2015

\section{KEY WORDS :}

Divergence, Wheat, Cluster, Gluten content, Genetic improvement

*Corresponding author:

Email: kharemudra22@gmail.com

\begin{abstract}
Genetic diversity of the thirty Mexican wheat (Triticum aestivum L.) genotypes were evaluated on the basis of ten different traits in Randomized Block Design during Rabi season, 2007 2008. These genotypes were grouped into six different clusters by using Mahalanobis $\mathrm{D}^{2}$ analysis. Cluster V had maximum number of (12) genotypes while, cluster I had only one genotypes. Distribution pattern of all the genotypes into various clusters showed the presence of considerable genetic divergence among the genotypes for most of the traits studied. Maximum generalized distances were observed between clusters I and VI. Yield per plant, gluten content (\%) and plant height showed maximum contribution to the total genetic divergence. The genotypes present in cluster I and VI may be used as parents in hybridization programmes to develop high yielding wheat varieties.
\end{abstract}

How to view point the article : Khare, Mudra, Rangare, N.R., and Singh, Ravi P. (2015). Evaluation of genetic diversity in Mexican wheat (Triticum aestivum L.) genotypes for qualitative and quantitative traits. Internat. J. Plant Protec., 8(1) : 77-80. 